\title{
Stress Analysis of Steel Structure Comprising Cylindrical Shell with Billboard Tower
}

\author{
Dorin RADU, Aleksandar SEDMAK, Simon SEDMAK, Momčilo DUNJIĆ
}

\begin{abstract}
In accordance with EN1993-1-1, in the definition of element classes, the tubular cross section elements are considered as class 3 for cross section that respects the relation: $d / t \leq 90 \varepsilon^{2}$. If for any cross section this relation is not satisfied, the norm is not valid and the cross section is classified as a curved thin walled element - shell element. Thus the design is done according to EN 1993-1-6 normative. The paper presents some aspects regarding the shell design for a case study - a $30 \mathrm{~m}$ tall billboard pillar. The designing process is detailed in regard to the used analysis and the ultimate limit states checking. Considering the high stress concentration in the area of the segment joints, design of welded joints is also presented. The Finite Element Method (FEM) is applied as well, showing results in agreement with analytical ones.
\end{abstract}

Keywords: finite element method; steel shell structures; stress analysis

\section{INTRODUCTION}

In order to design shell steel structures, both simplified and complex, analysis methods can be used. Simplified methods are based on analytical formulae for determining the bifurcation critic load, plastic limit capacity, sensitivity to imperfections, elastic-plastic interaction and the combining efforts mode. Advanced step is to find the bifurcation critical force of the plastic limit capacity using finite element method.

The most complete and complex approach is based on the numerical evaluation (using FEM software) of the parameters that are involved in dimensioning of the element: determining the critical bifurcation load following a stability analysis and determining the plastic capacity of the element following a non-linear analysis. Thus, in accordance with $[1,2]$, for designing thin shell structures, there are four limit states (LS): LS1 - plastic limit, LS2 - cyclic plasticity, LS3 - Stability and LS4 - fatigue. The present paper is considering the design procedures and a case study for LS1 and LS3 limit states.

The EN normative [1-3] provides the following designing possibilities for shell structures: using and comparing the stresses with the von Misses equivalent stress in the most strained point; through direct designing using the normative analytical relations; using a global numerical analysis through a FEM software.

Thus the design should be based on one or more types of analysis: membrane theory of shells (membrane equilibrium), linear elastic shell analysis (LA) (linear bending and stretching), linear elastic bifurcation analysis (LBA) (linear bending and stretching), geometrically non-linear elastic analysis (GNA) (non-linear), materially non-linear analysis (MNA) (linear), geometrically and materially nonlinear analysis (GMNA), geometrically non-linear elastic analysis with imperfections (GNIA), geometrically and materially non-linear analysis with imperfections (GMNIA).

\section{GLOBAL NUMERICAL SIMPLIFIED ANALYSIS}

The design buckling resistance is determined from the amplification factor $r_{R d}$ applied to the design values $F_{E d}$ of the combination of actions for the relevant load case. Thus $F_{R d}=r_{R d} F_{E d} \cdot F_{R d}$ is obtained from the plastic reference resistance $F_{R p l}=r_{R p I} \cdot F_{E d}$ and the elastic critical buckling resistance $F_{c r}=r_{R c r} \cdot F_{E d}$, combining these to find the characteristic buckling resistance $F_{R k}=r_{R c k} \cdot F_{E d}$.

The plastic reference resistance ratio $r_{R p l}$ (Fig. 1) should be obtained by materially nonlinear analysis (MNA) as the plastic limit load under the applied combination of actions. This load ratio $r_{R p l}$ may be taken as the largest value attained in the analysis, ignoring the effect of strain hardening.

Where it is not possible to undertake a materially nonlinear analysis, the plastic reference resistance ratio $r_{R p l}$ may be conservatively estimated from linear shell analysis (LA) conducted using the design values of the applied combination of actions. Thus the evaluated membrane stress resultants $n_{x, E d,}, n_{\theta, E d}$ and $n_{x \theta, E d}$ at any point in the shell should be used to estimate the plastic reference resistance:

$$
r_{R p l}=\frac{t \cdot f_{y k}}{\sqrt{n_{x, E d}^{2}-n_{x, E d} \cdot n_{\theta, E d}+n_{\theta, E d}^{2}+n_{x \theta, E d}^{2}}}
$$

The lowest value of plastic resistance ratio calculated in this way will be taken as the estimate of the plastic reference resistance ratio $r_{R p l}$. The relation will be verified in the three points in which the stresses reach the highest values.

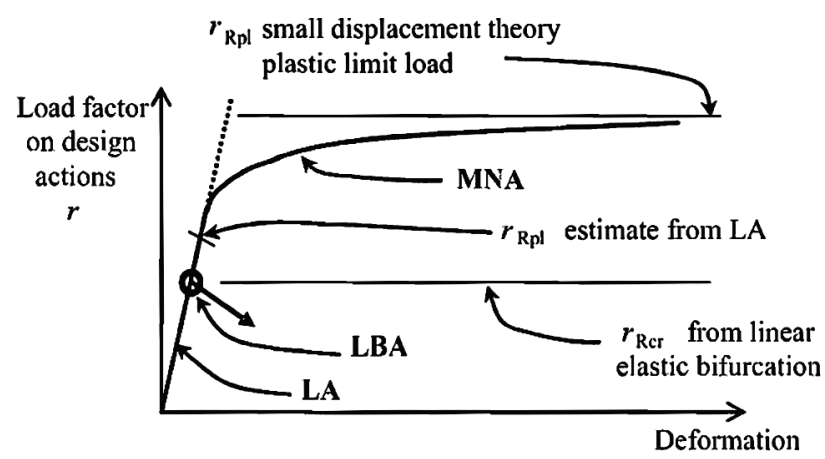

Figure 1 The plastic reference resistance ratio $r_{R p l}$ and critical buckling resistance ratio $r_{R c r}$ derived from global MNA and LBA analyses, [2]

The elastic critical buckling resistance ratio $r_{R c r}$ should be determined from an eigenvalue analysis (LBA) applied to the linear elastic calculated stress state in the geometrically perfect shell (LA) under the design values of the load combination. The lowest eigenvalue 
(bifurcation load factor) should be taken as the elastic critical buckling resistance ratio $r_{R c r}$ (Fig. 1).

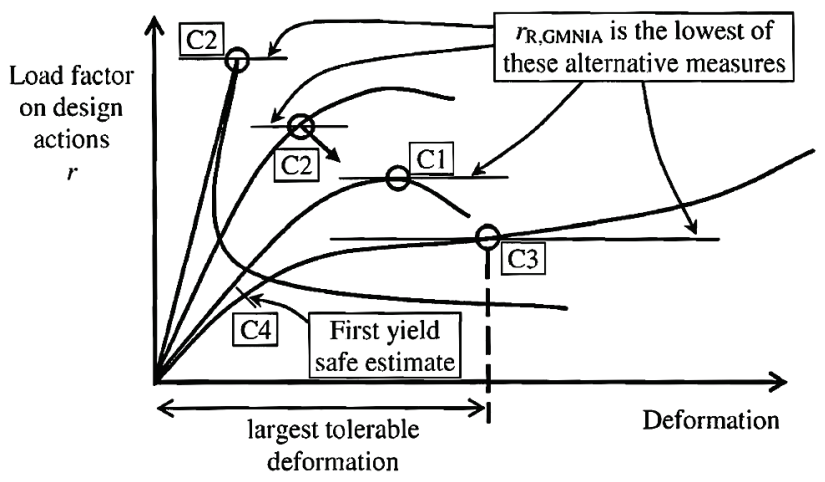

Figure 2 Definition of buckling resistance from global GMNIA analysis [2]

\section{COMPLETE NUMERICAL GLOBAL ANALYSIS}

The imperfect elastic-plastic buckling resistance ratio $r_{R, G M N I A}$ should be found as the lowest load factor $r_{R}$ obtained from the three following criteria $\mathrm{C} 1, \mathrm{C} 2$ and $\mathrm{C} 3$ (Fig. 3).

Criterion C1: The maximum load factor on the loaddeformation-curve (limit load);

Criterion C2: The bifurcation load factor, where this occurs during the loading path before reaching the limit point of the load-deformation-curve;

Criterion C3: The largest allowed deformation, where this occurs during the loading path before reaching a bifurcation load or a limit load.

A conservative assessment of the imperfect elasticplastic buckling resistance ratio $r_{R, G M N I A}$ may be obtained using a geometrically non-linear elastic analysis with imperfections (GNIA) of the geometrically imperfect shell under the applied combination of actions. In this case, the following criterion should be used to determine the lowest load factor $r_{R}$ :

Criterion C4: The load factor at which the equivalent stress at the most highly stressed point on the shell surface reaches the design value of the yield stress $f_{y d}=f_{y k} / \gamma \cdot M_{0}$ (Fig. 2).

In formulating the GMNIA (or GNIA) analysis, appropriate allowances should be incorporated to cover the effects of imperfections that cannot be avoided in practice, including: a) geometric imperfections, such as: deviations from the nominal geometric shape (predeformations, out of roundness); irregularities at and near welds (minor eccentricities, shrinkage depressions, rolling curvature errors); deviations from nominal thickness; lack of evenness of supports. b) material imperfections, such as: residual stresses caused by rolling, pressing, welding, straightening.

The imperfections should generally be introduced by means of equivalent geometric imperfections in the form of initial shape deviations perpendicular to the middle surface of the perfect shell, unless a better technique is used. The middle surface of the geometrically imperfect shell will be obtained by superposition of the equivalent geometric imperfections on the perfect shell geometry.

The correctness of the imperfect elastic-plastic buckling resistance ratio $r_{R, G M N I A}$, numerically determined, must be validated throughout numerical analysis conside- ring the same procedures and parameters and comparing the numerical models and experimental results.

\section{ULTIMATE LIMIT STATE DESIGN - ANALYTIC DESIGN}

Following the loads and element types, Eurocode ([2]) requests to take into account four types of limit states: plastic limit state (LS1), cyclic plasticity limit state (LS2), buckling limit state (LS3) and fatigue limit state (LS4).

For LS1 limit state, the designing is done by determining the stress design values. Although stress design is based on an elastic analysis and therefore cannot accurately predict the plastic limit state, it may be used, on the basis of the lower bound theorem, to provide a conservative assessment of the plastic collapse resistance which is used to represent the plastic limit state.

In this case Ilyushin yield criterion is used - rather conservative criterion, mainly because it only considers yield at a single point - not an incremental mechanism. Thus at each point in the structure the design value of the stress $\sigma_{e q, E d}$ should be taken as the highest primary stress determined in a structural analysis that considers the laws of equilibrium between imposed design load and internal forces and bending moments.

Using a membrane theory analysis, the resulting twodimensional field of stress resultants $n_{x, E d}, n_{\theta, E d}$ and $n_{x \theta, E d}$ may be represented by the equivalent design stress $\sigma_{e q, E d}$ obtained from:

$$
\sigma_{e q, E d}=\frac{1}{t} \sqrt{n_{x, E d}^{2}+n_{\theta, E d}^{2}-n_{x, E d} \cdot n_{\theta, E d}+3 n_{x \theta, E d}^{2}}
$$

where LA or GNA analysis is used. The resulting twodimensional field of primary stresses may be represented by the von Misses equivalent stress:

$$
\sigma_{e q, E d}=\sqrt{\begin{array}{l}
\sigma_{x, E d}{ }^{2}+\sigma_{\theta, E d}{ }^{2}-\sigma_{x, E d} \cdot \sigma_{\theta, E d}+ \\
3 \cdot\left(\tau_{x, \theta, E d}^{2}+\tau_{x, n, E d}^{2}+\tau_{\theta, n, E d}^{2}\right)
\end{array}}
$$

where:

$$
\begin{aligned}
& \sigma_{x, E d}=-\frac{N_{E d}}{2 \cdot \pi \cdot r \cdot t}+\frac{M_{y, E d}}{\pi \cdot r^{2} \cdot t} \pm \frac{M_{z, E d}}{\pi \cdot r^{2} \cdot t} \\
& \sigma_{\theta, E d}=\left(q_{e q}+q_{s}\right) \cdot\left(\frac{r}{t}\right) \\
& \tau_{x, \theta, E d}=\frac{M_{t, E d}}{2 \cdot \pi \cdot r^{2} \cdot t} \pm \frac{V_{z, E d}}{\pi \cdot r \cdot t} \\
& \text { and } \tau_{x, n, E d}=\frac{q_{x n, E d}}{t} \tau_{\theta, n, E d}=\frac{q_{\theta n, E d}}{t} .
\end{aligned}
$$

Due to their low values, $\tau_{x, n, E d}$ and $\tau_{\theta, n, E d}$ can be neglected.

The $q_{e q}$ is the equivalent distribution of the wind load onto the cylinder surface (Fig. 3).

The stresses are limited to: $\sigma_{e q, R d} \leq f_{e q, R d}$, where $f_{e q, R d}=f_{\gamma k} / \gamma \cdot M_{0}$. For LS3 limit state, the buckling resistance is represented by the design buckling stresses, which are 
obtained from the following relations: $\sigma_{x, R d}=\sigma_{x, R k} / \gamma_{M 1}$, $\sigma_{\theta, R d}=\sigma_{\theta, R k} / \gamma_{M 1}, \tau_{x \theta, R d}=\tau_{x \theta, R k} / \gamma_{M 1}$.
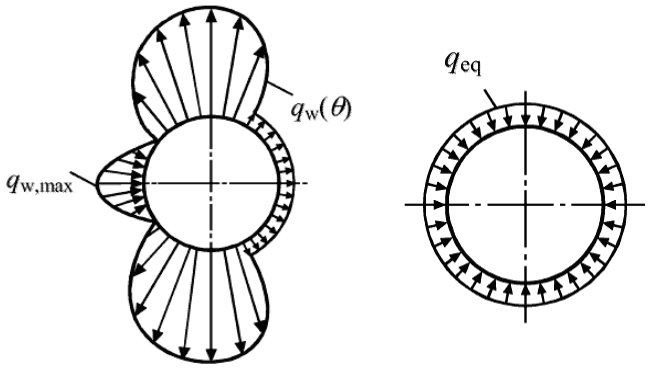

Figure 3 Transformation of the wind pressure distribution - (a) Wind pressure distributed around the shell circumference; (b) equivalent axial symmetric pressure distribution

The characteristic buckling stresses should be obtained by multiplying the characteristic yield strength by the buckling reduction factors $\chi$.

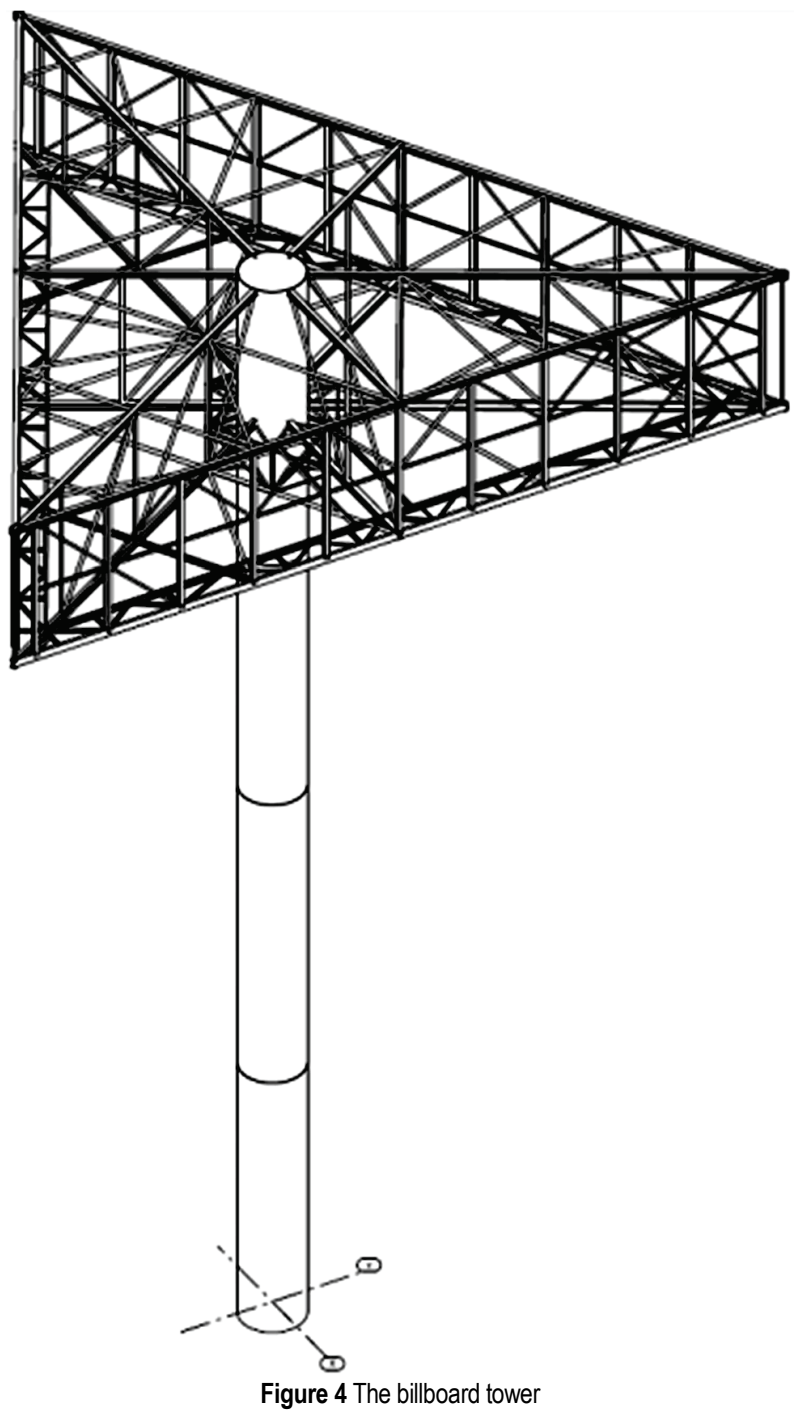

5 CASE STUDY - DESIGN OF $30 \mathrm{~m}$ TALL BILLBOARD TOWER

\subsection{Loads Evaluation and linear Analysis - Entire Model}

The case study presents the global analysis and the simplified designing of $30 \mathrm{~m}$ height tower elements - only the pillar. The structure has two components: the column which is a $1680 \mathrm{~mm} \mathrm{S355}$ steel quality tube and the head of the tower where the billboard is fixed. The head is made of a truss system in order to undertake the dead and wind loads and to transmit them directly to the pillar (Figs. 4 and 5).

Due to the triangular shape of the billboard area structure, and the size of the billboard ( $21 \mathrm{~m}$ length), the wind loads evaluation must be in depth evaluated. The EN 1991-1-4 [3] norm was used, considering the National Annexes for Netherland, where the pillar is located.

The pillar is made of four sections - from the base to the top: Tube $1680 \times 20 \mathrm{~mm}-7 \mathrm{~m}$, Tube $1680 \times 16 \mathrm{~mm}-8$ $\mathrm{m}$, Tube $1680 \times 12-7 \mathrm{~m}$ and Tube $1680 \times 10-8 \mathrm{~m}$ (Fig. $5)$. The sections are joined by bolted endplate connections with the bolts into the interior of the cylinder.

For the model was considered self-weight, dead load, live load (for maintenance), wind load and a geometric imperfection. The imperfection was taken into account as presented in EN1993-3-2 [4] - Chimneys:

$\Delta=\frac{h}{500} \sqrt{1+\frac{50}{h}}=\frac{30,00}{500} \sqrt{1+\frac{50}{30,00}}=0,0979 \mathrm{~m}$.

The wind load was evaluated as concentrated forces and as radial pressure on the column surface (Fig. 3). The wind load on the billboard was designed according to [3] - billboards. In Tab. 1 are presented the forces on the tower from the wind action. Following a dynamic analysis of the structure, results a frequency of $\eta_{1 x}=0,69 \mathrm{~Hz}$, thus the calculated coefficient $c_{s c d}=0,984$ [3].

\begin{tabular}{|c|c|} 
Table 1 Wind load forces at different heights \\
\begin{tabular}{|c|c|}
\hline$h(\mathrm{~m})$ & $q_{p}(z)\left(\mathrm{kN} / \mathrm{m}^{2}\right)$ \\
\hline 2.00 & 0.352 \\
\hline 4.00 & 0.492 \\
\hline 6.00 & 0.582 \\
\hline 8.00 & 0.648 \\
\hline 10.00 & 0.702 \\
\hline 12.00 & 0.747 \\
\hline 14.00 & 0.786 \\
\hline 16.00 & 0.820 \\
\hline 18.00 & 0.851 \\
\hline 20.00 & 0.879 \\
\hline 22.00 & 0.904 \\
\hline 24.00 & 0.928 \\
\hline 26.00 & 0.950 \\
\hline 28.00 & 0.970 \\
\hline
\end{tabular}
\end{tabular}

The wind force on the billboard area was calculated according to [3], Ch. 7.4.3:

$F_{w}=c_{s} \cdot c_{d} \cdot c_{f} \cdot q_{p}(z e) \cdot A_{r e f}$

resulting in total wind force of $F_{w}=146.664 \mathrm{kN}$.

According to [3], Ch.7.9.1, the pressure onto the cylinder (tower) was determined. The pressure coefficients depend on the Reynolds number Re, defined by

$\operatorname{Re}=\frac{b \cdot v\left(z_{e}\right)}{v}$

with $v=15 \times 10^{-6} \mathrm{~m}^{2} / \mathrm{s}$ (kinematic viscosity of the air) and $b=1,68 \mathrm{~m}$ (diameter of the pillar), and: 
$v\left(z_{e}\right)=\sqrt{\frac{2 \cdot q_{p}\left(z_{e}\right)}{\rho}}-39,403 \mathrm{~m} / \mathrm{s}$
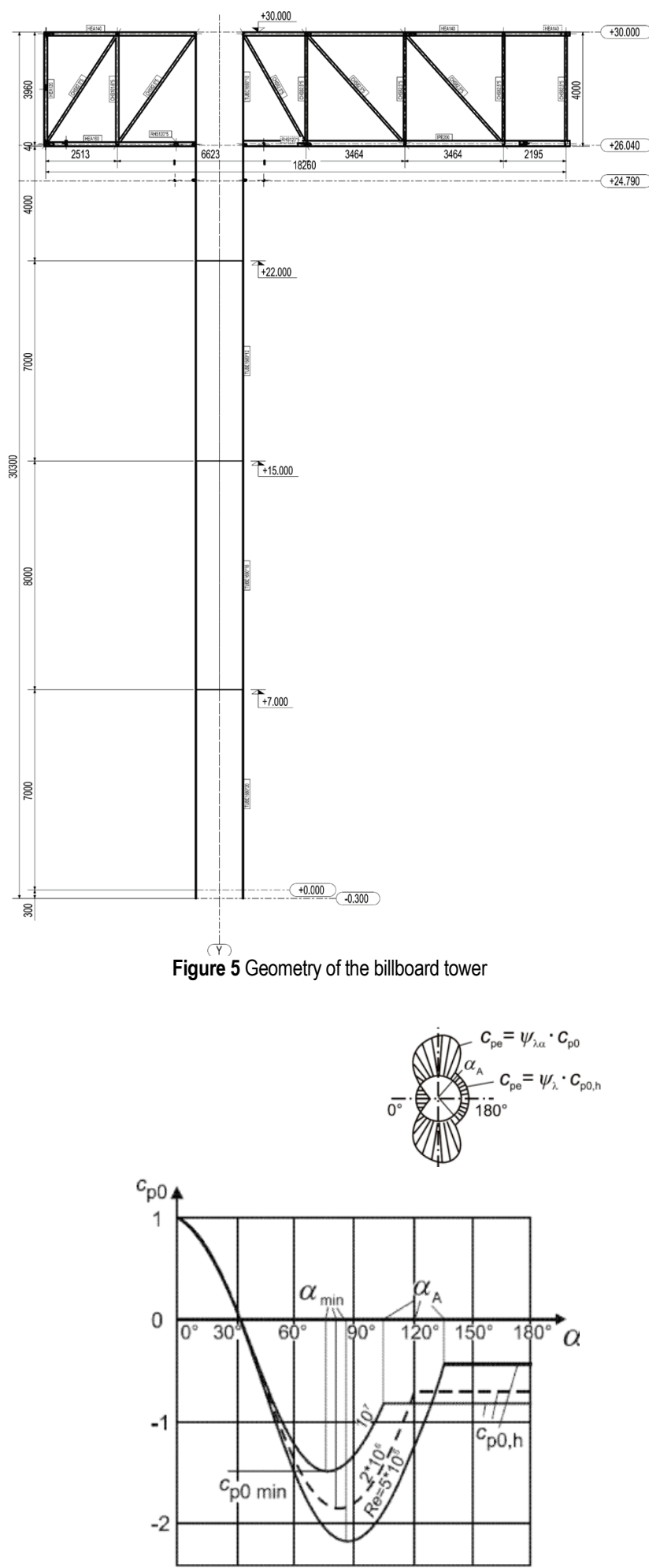

Figure 6 Pressure distribution for cylinders for different Reynolds number values

Through interpolation (Fig. 6), the pressure coefficients for different positions - $\alpha$ values are shown in (Tab. 2).

In order to estimate the concentrated wind load, calculation of the force coefficients was done: $c_{f}=c_{f, 0} \cdot \psi_{\lambda}=0,562$. The concentrated wind load is
$F_{w}=c_{s} \cdot c_{d} \cdot c_{f} \cdot q_{p}\left(z_{e}\right) \cdot A_{r e f}$. In Tab. 3, the wind load forces are presented.

Table 2 Wind pressure coefficients

\begin{tabular}{|c|c|c|c|c|}
\hline$\alpha$ & $c_{p 0}$ & $\psi_{\lambda \alpha}$ & $c_{p e}$ & $w_{e}$ \\
\hline $0^{\circ}$ & 1 & 1,00 & 1 & 0,95 \\
\hline $30^{\circ}$ & 0,1 & 1,00 & 0,1 & 0,095 \\
\hline $60^{\circ}$ & $-1,25$ & 1,00 & $-1,25$ & $-1,187$ \\
\hline $90^{\circ}$ & $-1,65$ & 0,968 & $-1,597$ & $-1,517$ \\
\hline $120^{\circ}$ & $-0,75$ & 0,720 & $-0,540$ & $-0,513$ \\
\hline
\end{tabular}

Table 3 Wind load forces on the tower

\begin{tabular}{|c|c|c|c|c|c|}
\hline$z_{e}$ & $l$ & $A_{r e f}$ & $q_{p}\left(z_{e}\right)$ & $F_{w}$ & $F_{w} / l$ \\
\hline 2.00 & 2.00 & 3.36 & 0.352 & 0.665 & 0.333 \\
\hline 5.00 & 3.00 & 5.04 & 0.541 & 1.532 & 0.511 \\
\hline 9.00 & 4.00 & 6.72 & 0.676 & 2.555 & 0.639 \\
\hline 13.00 & 4.00 & 6.72 & 0.767 & 2.897 & 0.724 \\
\hline 17.00 & 4.00 & 6.72 & 0.836 & 3.157 & 0.789 \\
\hline 21.00 & 4.00 & 6.72 & 0.892 & 3.368 & 0.842 \\
\hline 24.00 & 3.00 & 5.04 & 0.928 & 2.628 & 0.876 \\
\hline 26.00 & 2.00 & 3.36 & 0.950 & 1.794 & 0.897 \\
\hline
\end{tabular}

Following the structural analysis, the internal forces are calculated and presented in Tab. 4.

Table 4 Internal forces on each section of the tower
\begin{tabular}{|c|c|c|c|c|c|c|c|}
\hline $\begin{array}{c}\text { Height } \\
\left(\begin{array}{c}\text { from-to }) \\
(\mathrm{m})\end{array}\right.\end{array}$ & $\begin{array}{c}\text { Cross section } \\
(D \times t)(\mathrm{mm})\end{array}$ & $\begin{array}{c}N_{e d} \\
(\mathrm{kN})\end{array}$ & $\begin{array}{c}V_{y, E d} \\
(\mathrm{kN})\end{array}$ & $\begin{array}{c}V_{z, E d} \\
(\mathrm{kN})\end{array}$ & $\begin{array}{c}M_{t, E d} \\
(\mathrm{kNm})\end{array}$ & $\begin{array}{c}M_{y, E d} \\
(\mathrm{kNm})\end{array}$ & $\begin{array}{c}M_{z, E d} \\
(\mathrm{kNm})\end{array}$ \\
\hline $22-30$ & $1680 \times 10$ & 372 & 130 & 224 & 1120 & 1430 & 673 \\
\hline $15-22$ & $1680 \times 12$ & 418 & 136 & 235 & 1110 & 3052 & 1611 \\
\hline $7-15$ & $1680 \times 16$ & 488 & 142 & 247 & 1111 & 4997 & 2731 \\
\hline $0-7$ & $1680 \times 20$ & 566 & 147 & 255 & 1111 & 6772 & 3749 \\
\hline
\end{tabular}

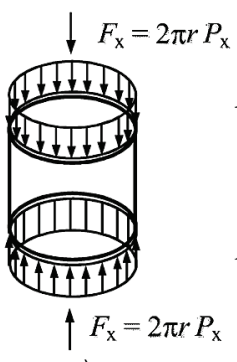

a)

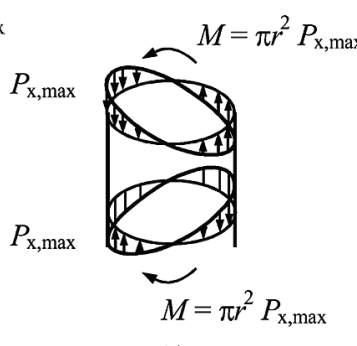

b)

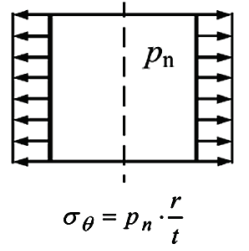

c)
Figure 7 Membrane theory stresses in unstiffened cylindrical shells: a) Axial uniform load; b) Axial load -global bending; c) Internal pressure

Following the linear analysis (LA), the buckling design forces are analytically calculated [2]. Determining the critical stresses, the meridian and circumferential stress, is done using annex D ([2]) - buckling design of the unstiffened shell element. The design of the stresses which appear in the walls of the tube pillar is done using annex A2 ([2]) using shell theory (Fig. 7). In case of circumferential stress following the wind load, an equivalent pressure $\left(q_{e q}\right)$ is considered which is uniformly distributed onto the surface of the cylinder $-k_{w}=0,165$ ([2], D.1.3.2 chapter).

The design results are presented in Tab. 5 for each limit state design - LS1 and LS3.

It can be noticed that the circumferential design buckling stress has low values $\left(\sigma_{\theta, R d}\right)$ in comparison with other design stresses, the dimensioning stress being the meridional design buckling stress $\left(\sigma_{x, R d}\right)$. The capacity of the elements (segments of the tower) is not exceeded, the maximum utilization factor being 0.94 (buckling checking), [5]. 
Finally, LA has been performed by the FEM, using the whole model. Stress distribution is shown in Fig. 7.
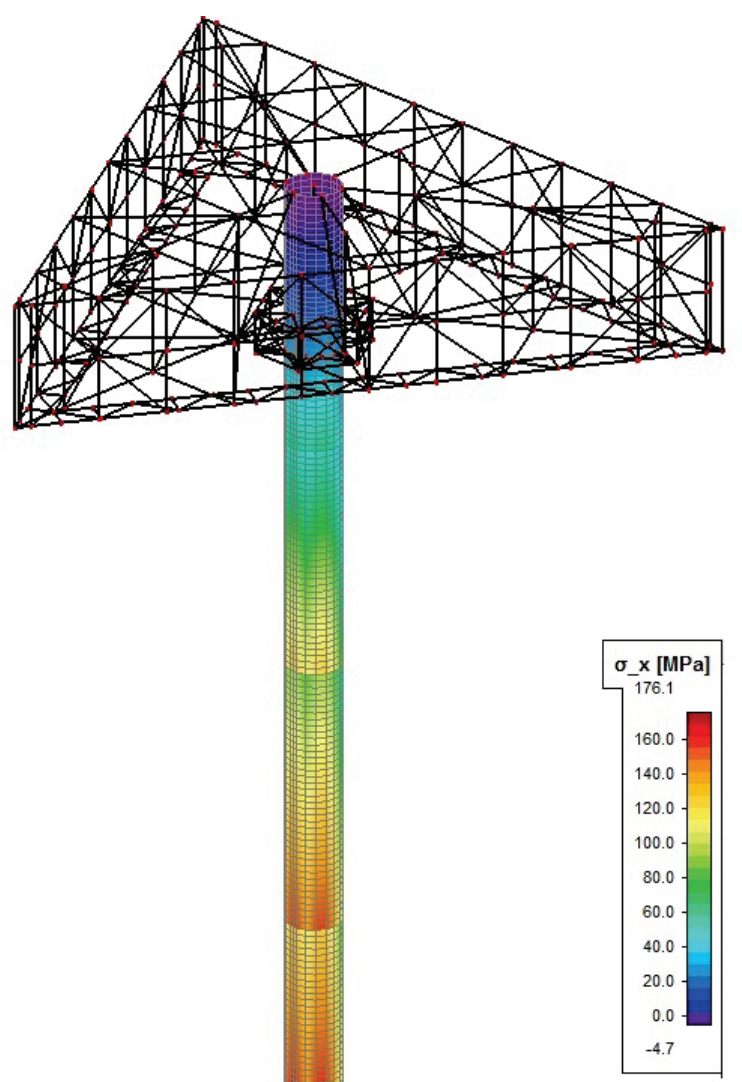

Figure 8 FEM LA (whole model): von Mises stresses ( $\max =177 \mathrm{MPa}$ )

Table 5 Design results - stress values and ratio of the elements following analytic design [2] - LA and buckling design stresses

\begin{tabular}{|c|c|c|c|c|c|}
\hline $\begin{array}{l}\text { Height } \\
\text { (m) }\end{array}$ & $\begin{array}{c}\text { Cross section } \\
(D \times t) \mathrm{mm}\end{array}$ & \multicolumn{2}{|c|}{$\begin{array}{c}\sigma_{x, E d} \\
(\mathrm{MPa})\end{array}$} & $\begin{array}{c}\sigma_{\theta, E d} \\
(\mathrm{MPa})\end{array}$ & $\begin{array}{c}\tau_{x \theta, E d} \\
(\mathrm{MPa})\end{array}$ \\
\hline $22-30$ & $1680 \times 10$ & \multicolumn{2}{|c|}{103,18} & 0,0552 & 33,909 \\
\hline $15-22$ & $1680 \times 12$ & \multicolumn{2}{|c|}{184,51} & 0,043 & 28,67 \\
\hline $7-15$ & $1680 \times 16$ & \multicolumn{2}{|c|}{227,98} & 0,032 & 21,88 \\
\hline $0-7$ & $1680 \times 20$ & \multicolumn{2}{|c|}{248,51} & 0,026 & 17,74 \\
\hline \multirow[b]{2}{*}{$\begin{array}{l}\text { Height } \\
\text { (m) }\end{array}$} & \multirow{2}{*}{$\begin{array}{l}\text { Cross section } \\
(D \times t) \mathrm{mm}\end{array}$} & \multicolumn{4}{|c|}{ LS1 } \\
\hline & & \multicolumn{2}{|c|}{$\sigma_{e q, E d}(\mathrm{MPa})$} & \multicolumn{2}{|c|}{$\begin{array}{l}\text { Rati } \\
\sigma_{e q R d} / \mathrm{c}\end{array}$} \\
\hline $22-30$ & $1680 \times 10$ & \multicolumn{2}{|c|}{118,7} & \multicolumn{2}{|c|}{0,334} \\
\hline $15-22$ & $1680 \times 12$ & \multicolumn{2}{|c|}{191,06} & \multicolumn{2}{|c|}{0,538} \\
\hline $7-15$ & $1680 \times 16$ & \multicolumn{2}{|c|}{231,09} & \multicolumn{2}{|c|}{651} \\
\hline $0-7$ & $1680 \times 20$ & \multicolumn{2}{|c|}{250,39} & \multicolumn{2}{|c|}{0,705} \\
\hline \multirow{2}{*}{$\begin{array}{l}\text { Height } \\
\text { (m) }\end{array}$} & \multirow{2}{*}{$\begin{array}{c}\text { Cross } \\
\text { section } \\
(D \times t) \mathrm{mm} \\
\end{array}$} & \multicolumn{4}{|c|}{ LS3 } \\
\hline & & $\begin{array}{c}\sigma_{x, R d} \\
(\mathrm{MPa})\end{array}$ & $\begin{array}{c}\sigma_{\theta, R d} \\
(\mathrm{MPa})\end{array}$ & $\begin{array}{c}\tau_{x \theta, R d} \\
(\mathrm{MPa})\end{array}$ & Ratio \\
\hline $22-30$ & $1680 \times 10$ & 207,96 & 3,78 & 47,31 & 0,848 \\
\hline $15-22$ & $1680 \times 12$ & 226,44 & 5,45 & 59,48 & 0,96 \\
\hline $7-15$ & $1680 \times 16$ & 250,43 & 9,72 & 85,96 & 0,921 \\
\hline $0-7$ & $1680 \times 20$ & 265,54 & 15,25 & 107,26 & 0,936 \\
\hline
\end{tabular}

\subsection{Advanced Analysis - Segment with Joints}

According to [2, 6-9], an advanced FEM analysis was done. With ABAQUS FEM software the model of three segments was designed, joined together with endplate bolted joints (Fig. 10). In order to evaluate the stresses around the joints, the model consists of one segment, two flange joints and is extended $1 \mathrm{~m}$ on bottom and top with additional segments (Fig. 9).

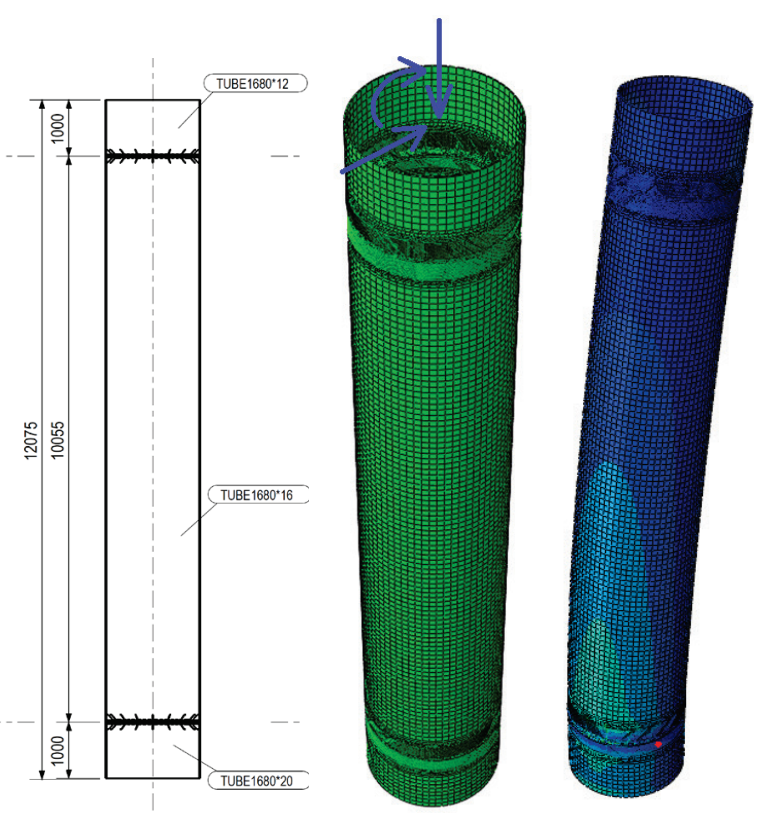

Figure 9 Geometry and the finite element model (unloaded and loaded) and loading values

Table 6 Loads on the top of the segment with joints model

\begin{tabular}{|c|c|c|c|c|c|}
\hline$N(\mathrm{kN})$ & $V_{y}(\mathrm{kN})$ & $V_{z}(\mathrm{kN})$ & $M_{x}(\mathrm{kN} \cdot \mathrm{m})$ & $M_{y}(\mathrm{kN} \cdot \mathrm{m})$ & $M_{z}(\mathrm{kN} \cdot \mathrm{m})$ \\
\hline-412.04 & 135.55 & -234.21 & 1110.89 & 2815.83 & -1475.2 \\
\hline
\end{tabular}

The segment model with joints was loaded with forces determined from LA analysis (Tab. 6). The forces were taken from the section from $1,00 \mathrm{~m}$ from the joint of the $12 \mathrm{~mm}$ thick segment and applied onto the top of the model. At the bottom (section $-1,00 \mathrm{~m}$ from the 20 to 16 $\mathrm{mm}$ segments joint), the model was considered fixed.
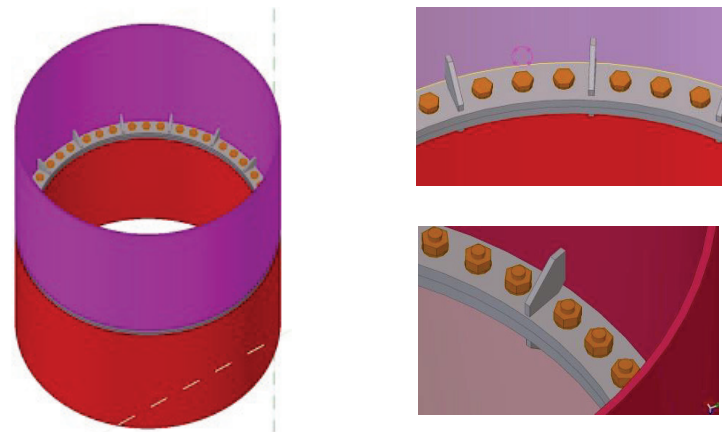

Figure 10 Joint of the tower segments

Table 7 Von Misses Maximum stress values comparison between LA entire model analysis and the three segments FEM analysis

\begin{tabular}{|c|c|c|}
\hline $\begin{array}{c}\text { Cross section } \\
(D \times t) \mathrm{mm}\end{array}$ & $\begin{array}{c}\text { LA analysis of the } \\
\text { entire model }(\mathrm{MPa})\end{array}$ & $\begin{array}{c}\text { FEM segments } \\
\text { analysis }(\mathrm{LA})(\mathrm{MPa})\end{array}$ \\
\hline $1680 \times 12$ & 184,51 & 178,20 \\
\hline $1680 \times 16$ & 227,98 & 204,10 \\
\hline $1680 \times 20$ & 248,51 & 221,11 \\
\hline
\end{tabular}

Following the design, it was noticed that the stress concentration is around joints elements (Fig. 11). The values of the stresses are close to the values taken from the linear elastic analysis, thus the model was verified. (Tab. 7).

Taking into account analytical results, and using the internal forces, stresses in the shell element are determined in the joint area [2]: 


$$
\begin{aligned}
& \sigma_{x, E d, 1}=-\frac{N_{E d}}{2 \cdot \pi \cdot r \cdot t}+\frac{M_{y, E d}}{\pi \cdot r^{2} \cdot t}+\frac{M_{z, E d}}{\pi \cdot r^{2} \cdot t}=216 \mathrm{MPa} \\
& \sigma_{x, E d, 2}=-\frac{N_{E d}}{2 \cdot \pi \cdot r \cdot t}-\frac{M_{y, E d}}{\pi \cdot r^{2} \cdot t}-\frac{M_{z, E d}}{\pi \cdot r^{2} \cdot t}=-228 \mathrm{MPa} \\
& \sigma_{x, E d}=\max \left(\left|\sigma_{x, E d, 1}\right|,\left|\sigma_{x, E d, 2}\right|\right)==228 \mathrm{MPa}
\end{aligned}
$$

The other stresses: $\sigma_{\theta, E d}, \tau_{x, \theta, E d, 1}, \tau_{x, \theta, E d, 2}, \tau_{x, \theta, E d}$, $\tau_{x, n, E d}$ and $\tau_{\theta, n, E d}$, having very low value, were neglected.
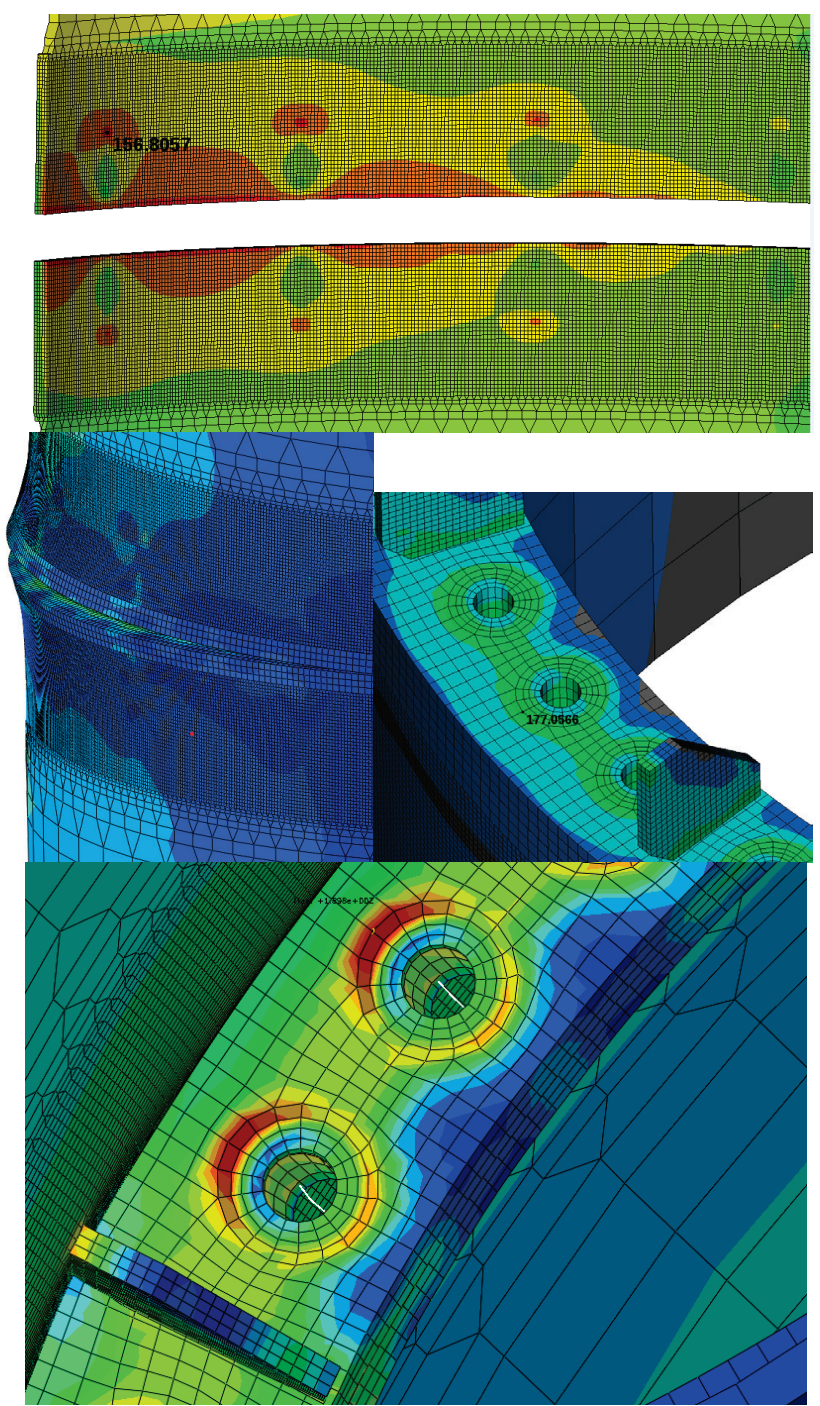

Figure 11 Stress results (Von Misses - MPa) following segments FEM analysis. Concentration of the stresses in the joint area

\subsection{LBA Analysis - Segment with Joints}

A linear buckling analysis (LBA) was performed to the perfect shell for the extreme wind load combination (taken from the Linear Analysis 1,35 $\times$ SelfWeight $+1,35$ $\times$ DeadLoad $+1,50 \times$ WindLoad X).

The elastic critical buckling resistance ratio $r_{R c r}$ is determined from an eigenvalue analysis (LBA) applied to the linear elastic calculated stress state in the geometrically perfect shell (LA) under the design values of the load combination.

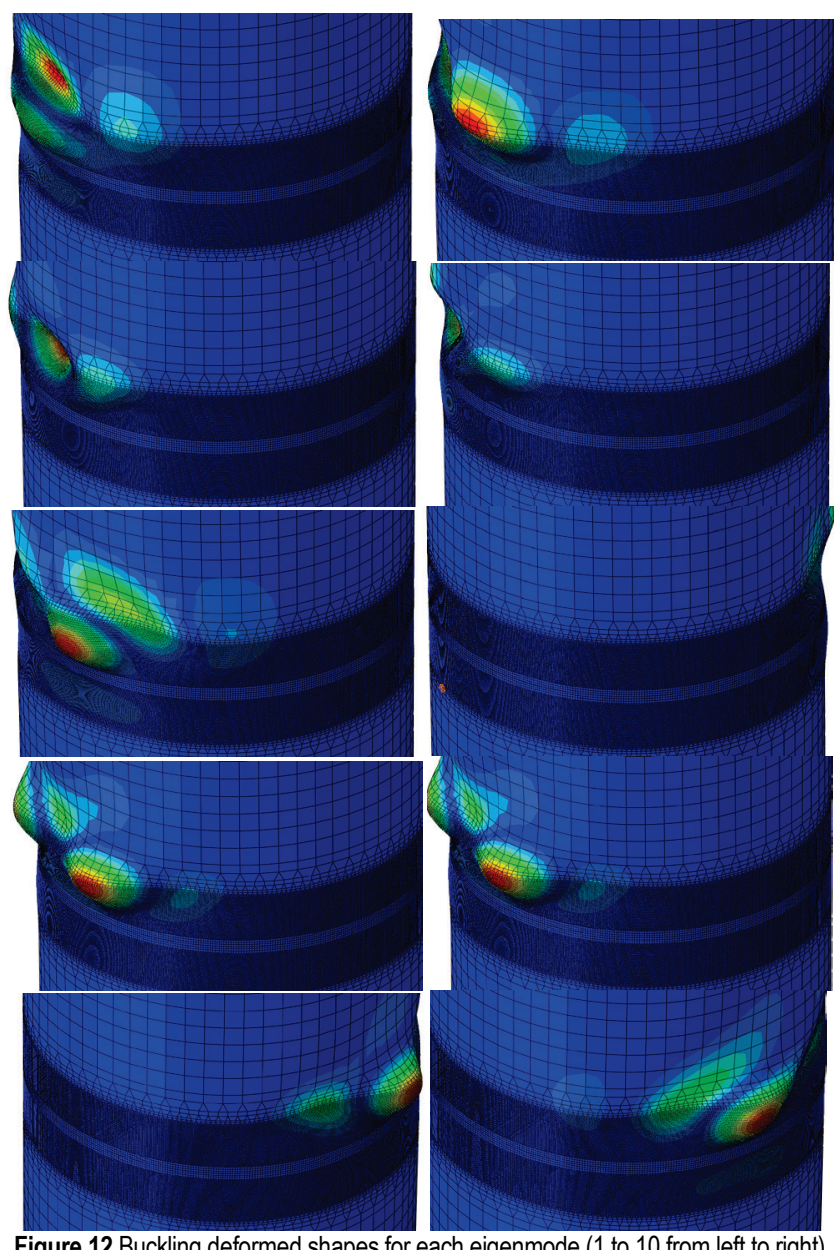

Figure 12 Buckling deformed shapes for each eigenmode (1 to 10 from left to right)

The first ten buckling eigenvalues were calculated, as presented in Fig. 12 and Tab. 8. The linear buckling eigenvalues represent the factors $r_{R c r}$ by the expression $r_{R c r}=$ $F_{R k} / F_{E d}$, where $F_{E d}$ represent the design loads and $F_{R k}$ the characteristic buckling resistance, at the bifurcation point.

Table 8 Design results - buckling eigenvalues $r_{R c r}$

\begin{tabular}{|}
\begin{tabular}{|c|c|c|c|c|c|}
\hline Eigenmode & {$[1]$} & {$[2]$} & {$[3]$} & {$[4]$} & {$[5]$} \\
\hline Eigenvalues $r_{R c r}$ & 1.154 & 1.021 & 1.199 & 1.010 & 1.240 \\
\hline Eigenmode & {$[6]$} & {$[7]$} & {$[8]$} & {$[9]$} & {$[10]$} \\
\hline Eigenvalues $r_{R c r}$ & 1.154 & 1.215 & 1.008 & 1.204 & 1.001 \\
\hline
\end{tabular}
\end{tabular}

All buckling eigenmodes present deformed shapes (buckling) at the lower part of the $16 \mathrm{~mm}$ thickness segment - nearby the joint area (immediately to the joint stiffeners).

The bifurcation load factor was taken as the first eigenmode corresponding value - critical buckling resistance ratio $r_{R c r}=1.154$ (Fig. 13).

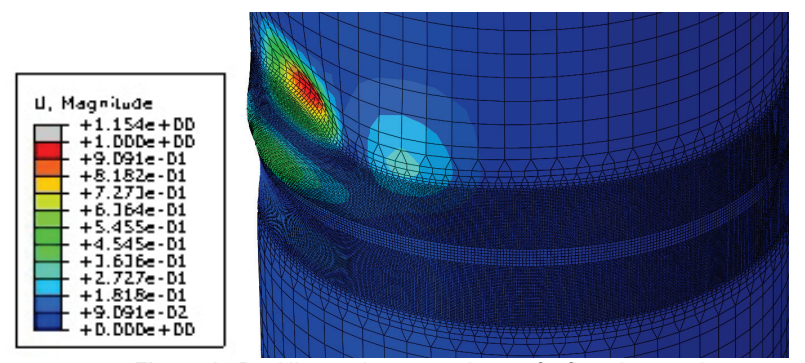

Figure 13 Buckling resistance ratio $r_{R c r}$ for first eigenmode 
The assessment of the stress values is presented in Tab. 9 - comparison between stress values (Von Misses) calculated analytically, [2],

Table 9 Von Misses Maximum stress values

\begin{tabular}{|c|c|}
\hline $\begin{array}{c}\text { Cross section } \\
(D \times t) \mathrm{mm}\end{array}$ & $\begin{array}{c}\text { Analytically calculated stresses (LS3- } \\
\text { buckling) }(\mathrm{MPa})\end{array}$ \\
\hline $1680 \times 12$ & 226,44 \\
\hline $1680 \times 16$ & 250,43 \\
\hline $1680 \times 20$ & 265,54 \\
\hline
\end{tabular}

As a first glance, the conclusion is that for the LS3 ultimate limit state design (buckling), [2], analytically calculated stresses are higher than the stresses obtained by the FEM analysis, which means that the Eurocode [2] is conservative.

\subsection{Joints Design - Flange to Cylinder Welded Joint}

Considering the high stress values in the area of the welded joint (as part of the segment end plated bolted joint), an assessment of the weld between the shell element and the endplate, was done.

In case of fillet welded joint, the internal stresses are decomposed in parallel and normal stresses type in critical section of the welded joint strip (Fig. 14), [10].

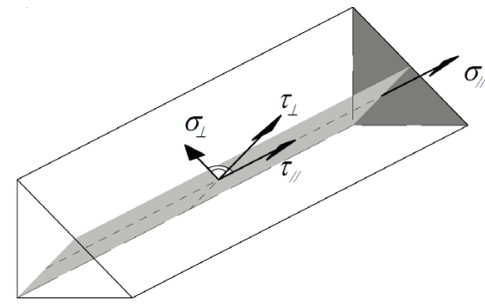

a)

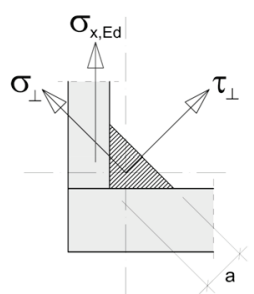

b)
Figure 14 (a) Stresses in the fillet welded joint critical plane; (b) stresses in the welded joint and stresses in the shell element

Considering a uniform distribution of the stresses in the critical section of the welded joint strip, the following tangential and normal stresses appear:

- $\sigma \perp$ - Normal stress perpendicular to the critical section of the welded joint strip

- $\sigma / /$ - Normal stress parallel to the welded joint strip axis

- $\tau \perp$ - Tangential stress in the critical cross section of the welded joint strip - perpendicular to the welded joint strip axis.

- $\tau / /$ - Tangential stress in the critical cross section of welded joint strip - parallel to welded joint strip axis

The design of the welded joint can be done with two methods: directional method and simplified method.

According to directional method, the strength of the welded joint will be sufficient if two conditions are fulfilled:

$\sqrt{\sigma_{\perp}^{2}+3 \cdot\left(\tau_{\perp}^{2}+\tau_{I I}^{2}\right)} \leq \frac{f_{u}}{\beta_{w} \cdot \gamma_{M 2}}$ and $\sigma_{\perp} \leq \frac{0,9 \cdot f_{u}}{\gamma_{M 2}}$

where $\beta_{w}$ represents a correlation coefficient according to steel type (Tab. 4.1. - [1]), and $f_{u}$ is the nominal value of the tension resistance of the weakest part of the joint.

The Eurocode [1] presents also a simplified procedure in order to assess the welded joint resistance without considering the load direction. Thus, irrespective of the welded joint designed area orientation toward the applied force, the resistance force $F_{w, R d}$, can be determined by relation:

$$
F_{w, R d}=f_{v w, d} \cdot a \text { where } f_{v w, d}=\frac{f_{u}}{\sqrt{3} \cdot \beta_{w} \cdot \gamma_{M 2}} .
$$

For the fillet joint from endplate to the segment tube, due to the directional section of the shell stresses $\sigma_{x, E d}$ the directional method was chosen for the design of welded joint. The analytically calculated values of the stresses were used in the joint design.

Due to the shell stress direction and the fillet welded joint strip stresses, from the sum of the projections, $\sigma_{\perp}=\frac{\sqrt{2}}{2} \cdot \sigma_{x, E d}=161,20 \mathrm{MPa}$

but also $\sigma_{\perp} \cdot \cos 45^{\circ}=\tau_{\perp} \cdot \sin 45^{\circ}$.Taking into account the same principle, one gets $\tau_{I I} \approx \sigma_{\theta, E d}$.

Proposing $a=10 \mathrm{~mm}\left(0.7 \times t_{\text {min }}=11.2 \mathrm{~mm}\right)$, the stresses in welded joint strip reach the value of:

$$
\sqrt{\sigma_{\perp}^{2}+3 \cdot\left(\tau_{\perp}^{2}+\tau_{\mathrm{II}}^{2}\right)}=322,4<\frac{f_{u}}{\beta_{w} \cdot \gamma_{M 2}}=453,22 \mathrm{MPa}
$$

Considering the checking formulae [4], one gets:

$$
\sigma_{\perp}=\frac{\sqrt{2}}{2} \cdot \sigma_{x, E d}=161,20<\frac{0,9 \cdot f_{u}}{\gamma_{M 2}}=367,2 \mathrm{MPa} .
$$

Thus, the welded joint has lower stress than the maximum allowable.

\section{CONCLUSION}

In the case of shell civil structures, the design is done in accordance with the European norm EN 1993-1-6. For a tall shell element (e.g. wind turbines towers, billboard towers) usually the circumferential design stress has low values $\left(\sigma_{\theta, R d}\right)$ in comparison with other design stresses, the dimensioning stress being the meridional design stress $\left(\sigma_{x, R d}\right)$. The welded joint in the segments joints type has high meridional stress.

The paper presents the design principles [2] for an analytical calculation and a case study - a billboard tower with a height of $40 \mathrm{~m}$, for which are calculated the stresses (analytically following LA analysis - LS3) and with detailed FEM analysis (LBA analysis). The values of the stress results are compared. The normative results are conservative in comparison with the calculated FEM detailed analysis for the presented case.

The results from the linear elastic bifurcation analyses indicate that the tower has been designed to reach the plastic limit load before approaching the bifurcation point.

The collapse is induced by the shell buckling at the plasticized areas, where the plasticizing Von Misses stresses are components of the compressive meridional 
and circumferential stresses (the meridional stresses being the high value ones).

It should be mentioned that fatigue limit state (LS4 named limit state $-[2]$ ) is not considered in the presented analyses.

Due to high stress in the joint area, a welded joint assessment is done, in terms of welded joint design welded joint between the segment cylindrical (shell) element and the bolded endplate.

Further research should involve the use of these results as the base for numerical calculating of LBA for structures that could be potentially subjected to buckling, both in order to obtain an efficient means LBA and to further confirm the accuracy and effectiveness of the method presented here.

\section{Acknowledgement}

This paper is extended version of the paper published in the Proceedings of the International conference TEAM 2015, held in Belgrade, referenced here as [5].

\section{References}

[1] European Committee for Standardisation (CEN). Eurocode 3. Design of steel structures, part 1-1: General rules Brussels; 2006

[2] European Committee for Standardisation (CEN). Eurocode 3. Design of steel structures, part 1-6: Strength and Stability of Shell Structures

[3] European Committee for Standardisation (CEN). Eurocode 1. Action on structures, part 1-4: Wind load

[4] European Committee for Standardisation (CEN). Eurocode 3. Design of steel structures, part 1-8: Joints design, Brussels; 2006

[5] Radu, D. \& Sedmak, A. (2015). Design of cylindrical shell steel structures with billboard tower as the case study, Proceedings of the International conference TEAM 2015, Belgrade / Serbia, 580-584.

[6] Maneski, T. \& Milošević-Mitić, V. (2010). Numeričkoeksperimentalna dijagnostika čvrstoće konstrukcija, Structural Integrity and Life Journal, 10(1), 3-10.

[7] Daničić, D. \& Maneski, T. (2012). The Structure Failure of the Discharge Boom of Bucket Wheel Excavator C $700 \mathrm{~S}$ due to Dynamic Effects, Structural Integrity and Life Journal, 12(1), 43-46.

[8] Bogatinoski, Z., Arsova-Milosevska, G., \& Trajanoska, B. (2010). Numerical Modelling of Beam-Column Connections at Multi-Storey Composite Structures, Structural Integrity and Life Journal, 10(3), 245-248.

[9] Ćosić, M., Folić, B., \& Sedmak, S. (2012). Buckling Analysis of 3D Model of Slender Pile in Interaction with Soil Using Finite Element Method, Structural Integrity and Life Journal, 12(3), 221-232.

[10] Sedmak, A. \& Radu, D. (2014). Truss Beams Welded Joints - Manufacturing Imperfections and Strengthening Solutions. Structural Integrity and Life Journal, 14(1), 2934.

\section{Contact information:}

Dorin RADU, Assistant

University of Transylvania, Faculty of Civil Engineering,

Turnului street no. 5, 500036 Brasov, Romania

E-mail: dorin.radu@unitbv.ro

\section{Aleksandar SEDMAK, Prof. PhD}

University of Belgrade, Faculty of Mechanical Engineering,

Kraljice Marije 16, 11120 Belgrade, Serbia

E-mail: asedmak@mas.bg.ac.rs

Simon SEDMAK, Researcher

Innovation of Faculty of Mechanical Engineering,

Kraljice Marije 16, 11120 Belgrade, Serbia

E-mail: simon.sedmak@yahoo.com

Momčilo DUNJIĆ, Assoc. Prof. PhD

University of Belgrade, Faculty of Mechanical Engineering,

Kraljice Marije 16, 11120 Belgrade, Serbia

E-mail: mdunjic@mas.bg.ac.rs 